\title{
Canada's health system is at a breaking point, say medical leaders
}

Cite as: CMAJ 2021 October 25;193:E1638. doi: 10.1503/cmaj.1095965

Posted on cmajnews.com on October 7, 2021

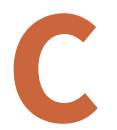
anada's fourth wave of COVID-19 is pushing health workers to the brink according to medical leaders who attended an emergency summit of nearly 40 health care organizations hosted by the Canadian Medical Association (CMA) and Canadian Nurses Association (CNA).

Medical leaders are hearing "unprecedented levels of concern coming from the front line around staffing shortages, morale and burnout," said CMA President Dr. Katharine Smart.

Yet, governments seem unwilling to acknowledge the toll that stop-gap measures like forced overtime and vacation blackouts are taking on health care workers.

"We are at a complete breaking point," Smart said. "It's really unclear how much longer people will be able to keep going, and we're already seeing people leaving the system because they just don't feel they can work in it anymore."

Some institutions have hundreds of job postings open for nursing staff "with not a single applicant," Smart said.

Meanwhile, Alberta and Saskatchewan have delayed thousands of surgeries to accommodate soaring hospitalizations after those provinces dropped pandemic restrictions despite health worker warnings.

Even in provinces like Ontario that haven't seen major surges in COVID-19 cases this fall, as many as three in four doctors report symptoms of burnout.

"If we don't take action now, we are going to decimate the health care system," Smart said. "That's the level of desperation that people within the system are feeling."

The CNA and CMA are calling on governments to prevent health systems from collapsing by implementing "circuit breaker" lockdowns, vaccine mandates, and other public health measures.

They also want "immediate relief" for health workers in COVID hot spots, including removing jurisdictional limits on medical licenses so health professionals from across the country can mobilize to cover staffing shortages.

So far, Alberta has accepted help from the Canadian Armed Forces and the Canadian Red Cross and reinstated restrictions on businesses and gatherings. But Smart said long-term solutions will require a comprehensive health human resources plan and mental health supports for health workers.

Without national planning and data, it's difficult to predict and respond to staffing shortages. "We don't really know the scale of the problem, or how to solve it, or what the investments need to be," Smart said.

Ensuring that health care workplaces are psychologically and physically safe is critical for staff well-being and retention. Yet, many clinicians face barriers on the job to accessing mental health supports, Smart said. "When you're forced to work constantly, when do you have any time to care for yourself or attend to your mental health or seek out resources that might be there to support you?"

\section{Diana Duong, CMAJ}

Content licence: This is an Open Access article distributed in accordance with the terms of the Creative Commons Attribution (CC BY-NC-ND 4.0) licence, which permits use, distribution and reproduction in any medium, provided that the original publication is properly cited, the use is noncommercial (i.e., research or educational use), and no modifications or adaptations are made. See: https://creativecommons.org/ licenses/by-nc-nd/4.0/ 